\title{
Correction to: Abdelmageed Abdelrahman MBBCh BAO DIPM DFSRH MRCOG MSc (clinical education)
}

\author{
Abdelmageed Abdelrahman ${ }^{1}$
}

Published online: 23 August 2021

(c) The International Urogynecological Association 2021

Correction to: International Urogynecology Journal (2021) 32:2177 https://doi.org/10.1007//s00192-021-04833-8

The original article was published with an incorrect title "Abdelmageed Abdelrahman MBBCh BAO DIPM DFSRH MRCOG MSc (clinical education)". The correct title should be:

Commentary on 'Timing of recurrence after surgery in pelvic organ prolapse'

Publisher's note Springer Nature remains neutral with regard to jurisdictional claims in published maps and institutional affiliations.

The original article can be found online at https://doi.org/10.1007/ s00192-021-04833-8.

Abdelmageed Abdelrahman

abdelmageed@hotmail.co.uk

1 Department of Urogynaecology, Liverpool Women's

HospitalNHS Foundation Trust, Liverpool, UK 